as well as my godfather, and I treasured the special attention he gave to me. It led to one of my most memorable times with him before he the piano with my "ndfather "Honey Fitz."

When Jack decided ior Congress in 1946 his Navy frierromente among the first to
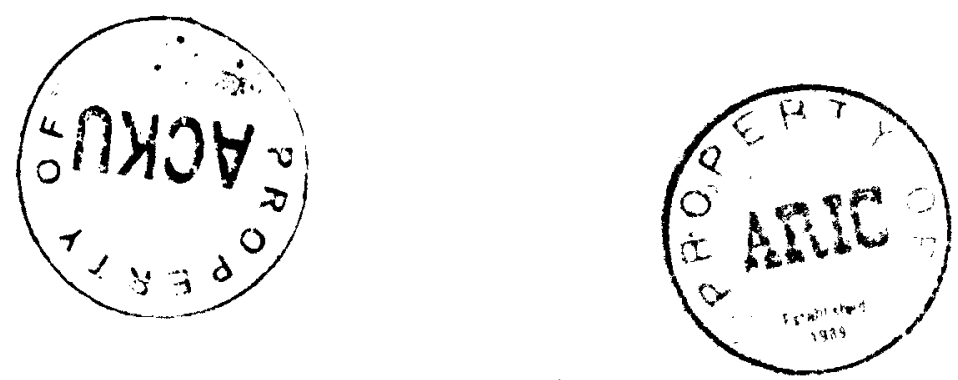

\title{
A new day in Kabul : after 24 years of war, Afghanistan's capital is breathing free. Can its fledgling recovery last?
}

National Geographic Society

Washington, DC

2003

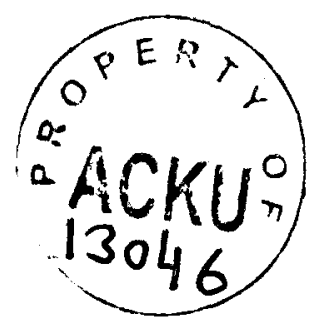

war club (above), still a treasured memento. 



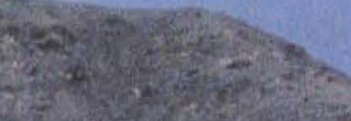

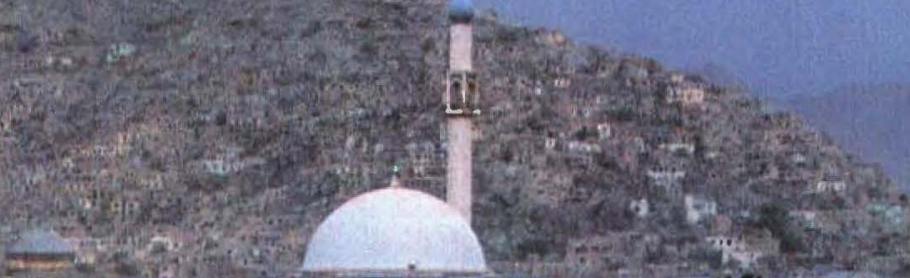

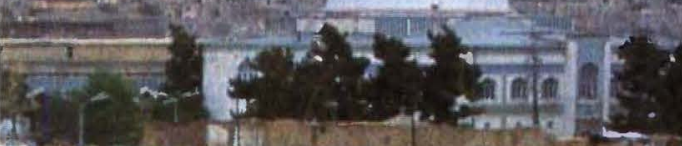

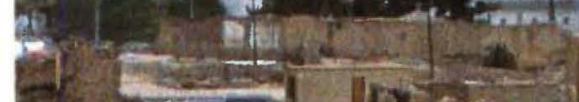

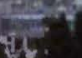

iv.

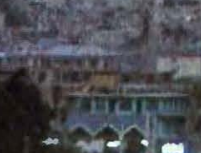

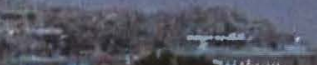

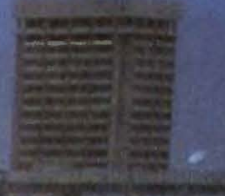

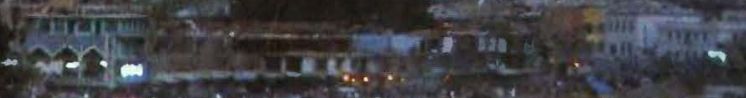

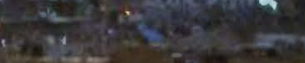

w.

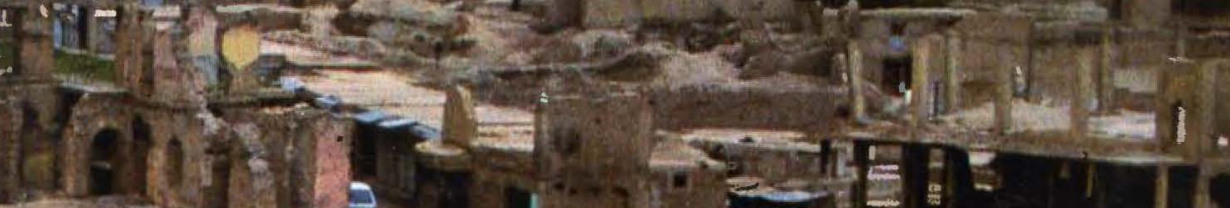

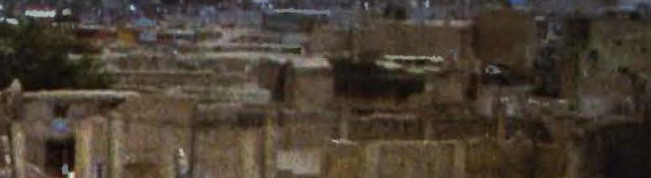

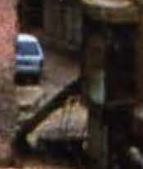

I.

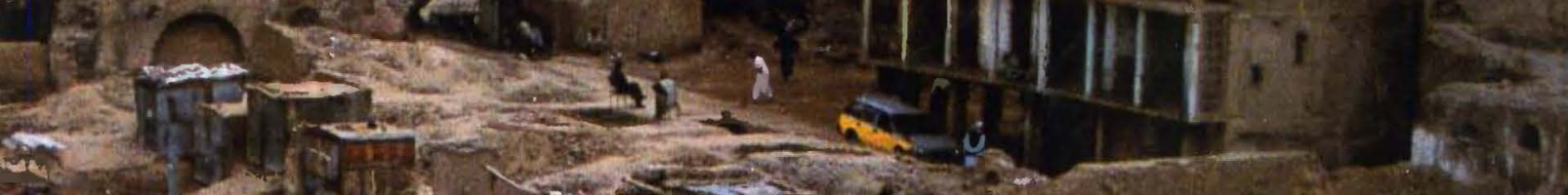

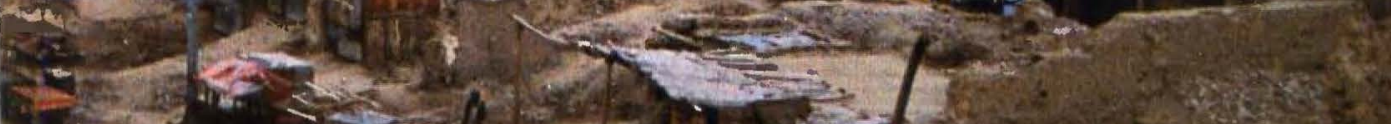

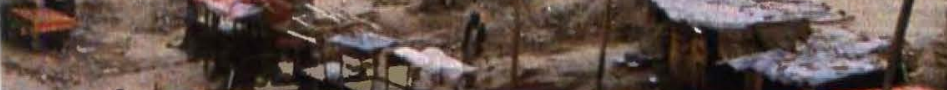

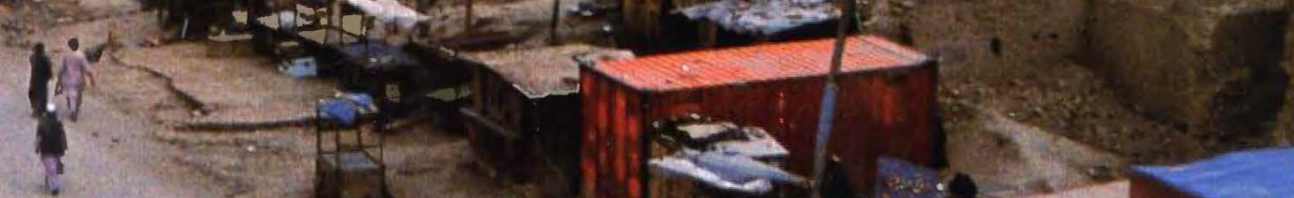
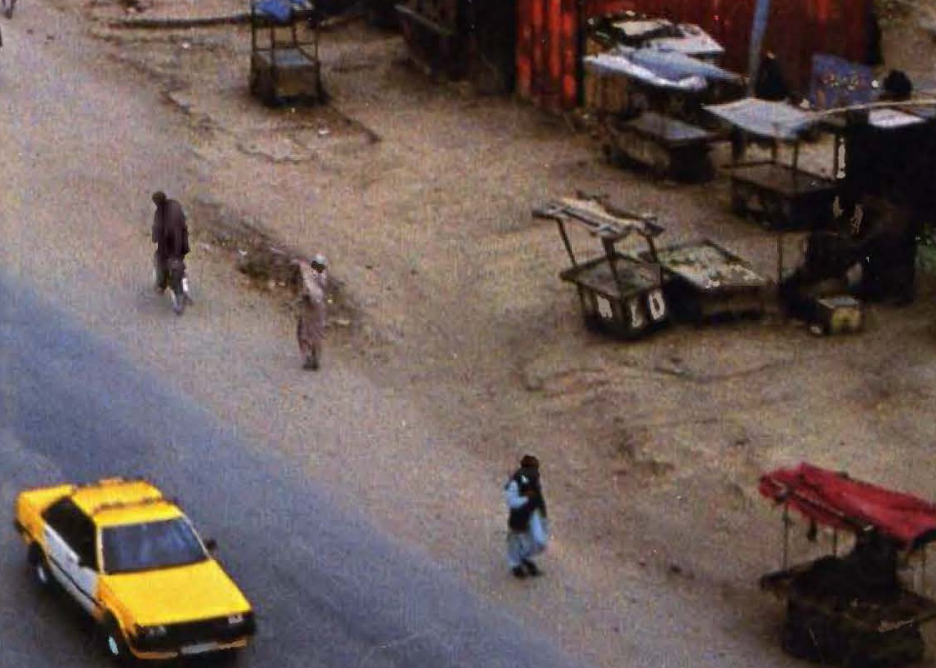

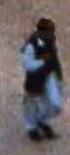

(1)

$\operatorname{cis}_{1}$

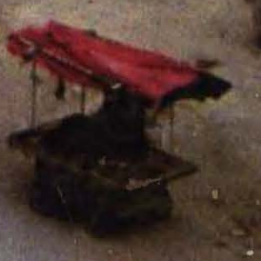

1. 


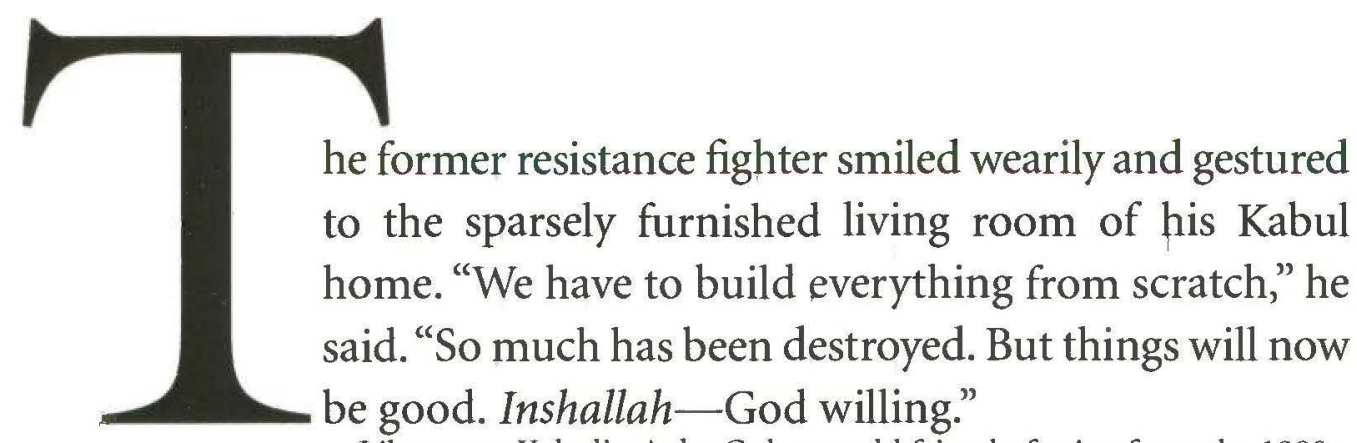

Like many Kabulis, Agha Gul - an old friend of mine from the 1980s, when I was covering and he was fighting the Soviet occupation-had lost his home several times during the various conflicts that ravaged Afghanistan over the past 24 years. From a bloody coup in 1978, to the Soviet war, to bitter factional fighting in the early 1990s, through stifling Taliban rule, the nation has known only hardship, with many of its towns and cities turned to ruins. Now, for the first time, I felt a genuine sense of optimism for the future. Kabul is finally beginning to live again.

The bazaars throng with merchants, returned refugees, former fighters, and farmers. Music blares from packed chaikhane, or teahouses, many of which sprout satellite dishes for television sets perpetually tuned, it seems, to the highly popular Indian movie or music channels previously banned under the Taliban. Shop stalls brim with imported goods ranging from Russian refrigerators and tires to Chinese teapots, as well as the latest CDs and DVDs at black market rates of barely a dollar each. On the outskirts of town, food markets overflow with produce, while nomads bring in their camels, sheep, and goats for sale.

Perhaps the most encouraging sign of the city's rebirth is the recent reopening of its schools, particularly the girls' schools, closed under the Taliban. Throughout the city, students, who attend class in shifts because of their overwhelming numbers, troop from class to home, many clutching plastic "Back to School" UNICEF bags. In backstreets and empty lots Afghans indulge in soccer and even cricket, imported by refugees from Pakistan. Many men have shaved their beards or keep them fashionably trimmed, while office workers increasingly wear suits and ties, expressing a form of modernity not seen in decades. In public most women still wear a full-length blue or gray chadri, or burka, either by choice or for fear of a fundamentalist backlash. Yet a determined and growing group of women, mainly educated professionals, now dare to be seen in long dresses with shawls carefully wrapped around their heads and shoulders - and with their faces free.

Freedom quickly translates to chaos on Kabul's streets, now clogged with yellow-and-white taxis, UN four by fours, and the military vehicles of international security forces. Uniformed policemen struggle to direct heedless drivers, often leaping into traffic to slap miscreants amid a slew of invectives, much to the amusement of jeering bystanders.

The onslaught of new cars, hotels, businesses, and investment is part of a recovery fueled by the enormous international presence, which is 


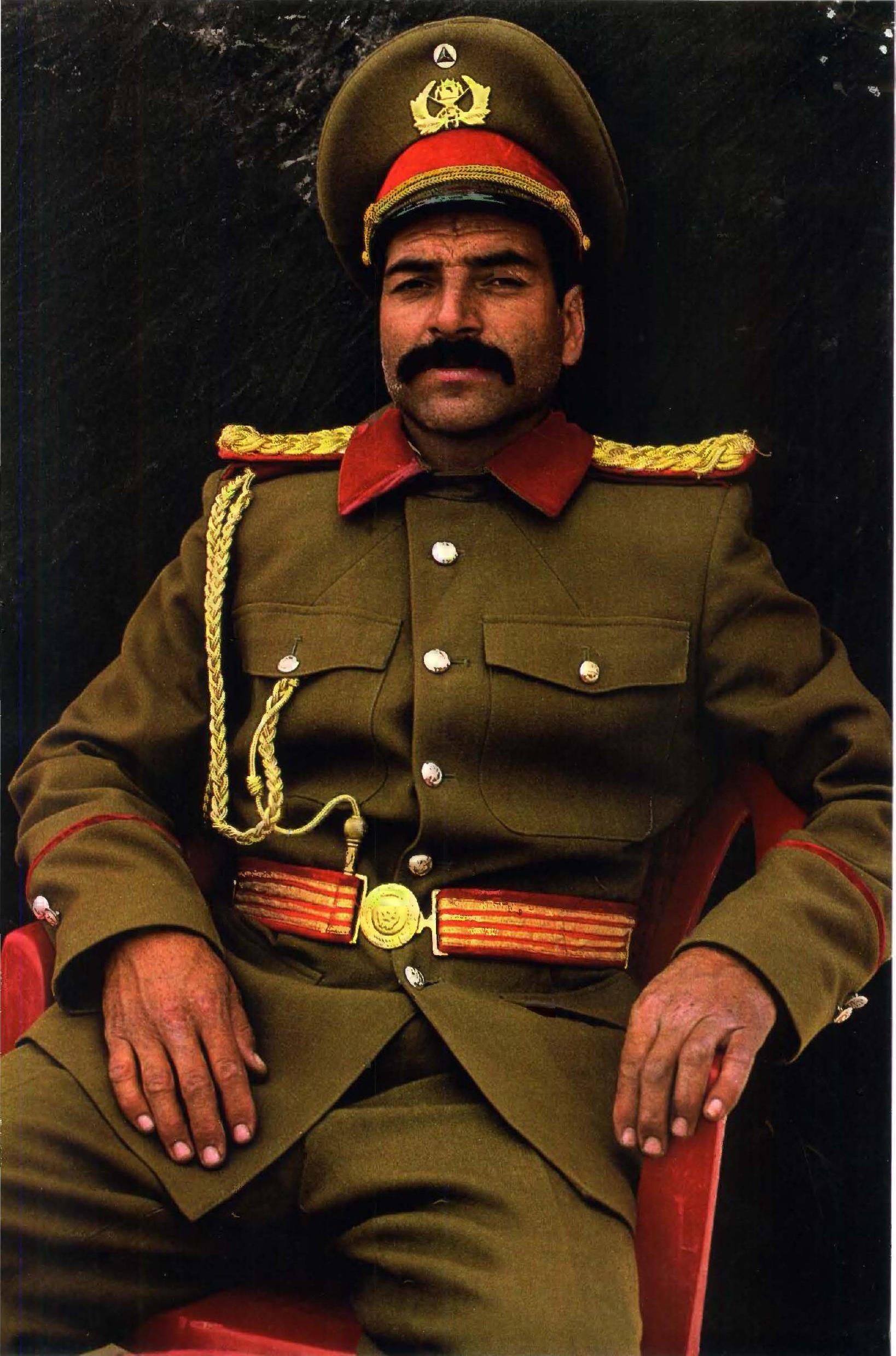




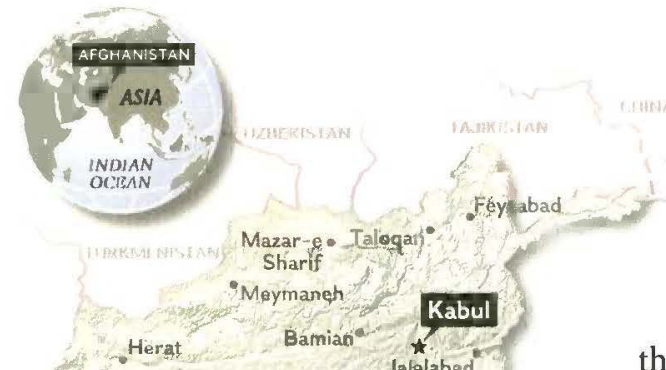

flooding Kabul with money, jobs, and a sense of security. Yet this presence is also creating an artificial environment of inflated salaries, rents, and expectations that cannot last-and that may obscure the city's very real challenges.

One only need stand on the mountains overlooking Kabul to grasp the extent of the damage inflicted by war. Entire quarters consist of little more than crumbling walls and collapsed roofs. Factories lie destroyed, warehouses have been looted down to the door frames, and red flags mark the suspected presence of hidden land mines and unexploded ordnance. Other, more insidious, dangers remain: Recent terrorist attacks in Kabul and elsewhere prove that political violence is an ongoing threat. Also, as returnees pour in, the city's population is soaring-estimates range from 1.5 to 2.5

POWER SHIFT

With crisp uniform and clean-shaven chin, an officer represents Afghanistan's new army. The military is led by loyalists of the Northern Alliance, which helped defeat the Taliban a year ago. Its longtime head, Ahmad Shah Massoud, was assassinated on September 9, 2001. Hailed as a hero in Kabul, his image is everywhere, even on rugs (right). This cult status angers some Afghans, who charge Massoud's followers with dominating and corrupting - the new government. million people - and Kabul is barely able to cope. Sewage is simply dumped into water channels, polluting wells. Water shortages, poor hygiene, and piles of garbage are boosting the dangers of cholera and dysentery. Leishmaniasis, an ulcerous skin disease, has become epidemic.

And yet the most immediate impression one has on arrival in Kabul is of exhilaration and confidence. Much of this stems from the holding of the Loya Jirga, or Grand Council, in June, which signaled for most Afghans the beginning of a new era with the election of a broad-based interim government. And though many Afghans, particularly Kabulis, regard the Loya Jirga as rigged, they also view it as the first time in decades that ordinary Afghans were able to express themselves openly.

For countless Afghans Kabul's renaissance represents a golden opportunity that cannot be squandered. I heard this voiced by Lateef Khalid, a 40 -year-old teacher who was preparing to return to Kabul after spending 20 years in Pakistan. "If we don't resolve our problems now," he said, "then we will have missed a chance that may never come again."

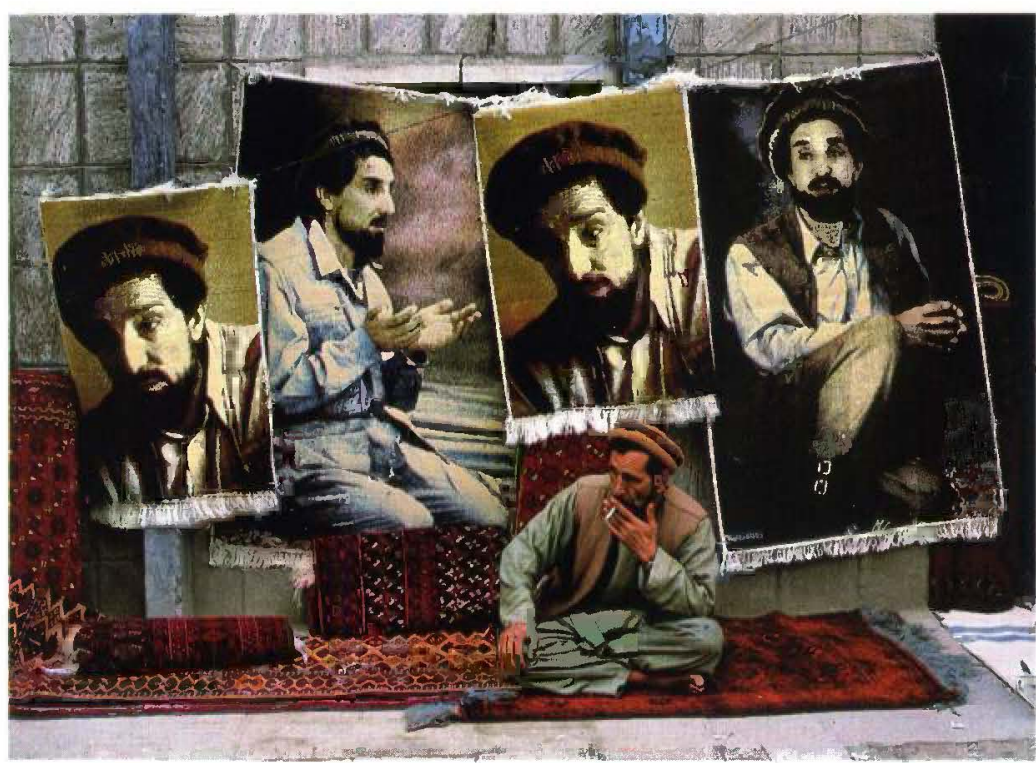




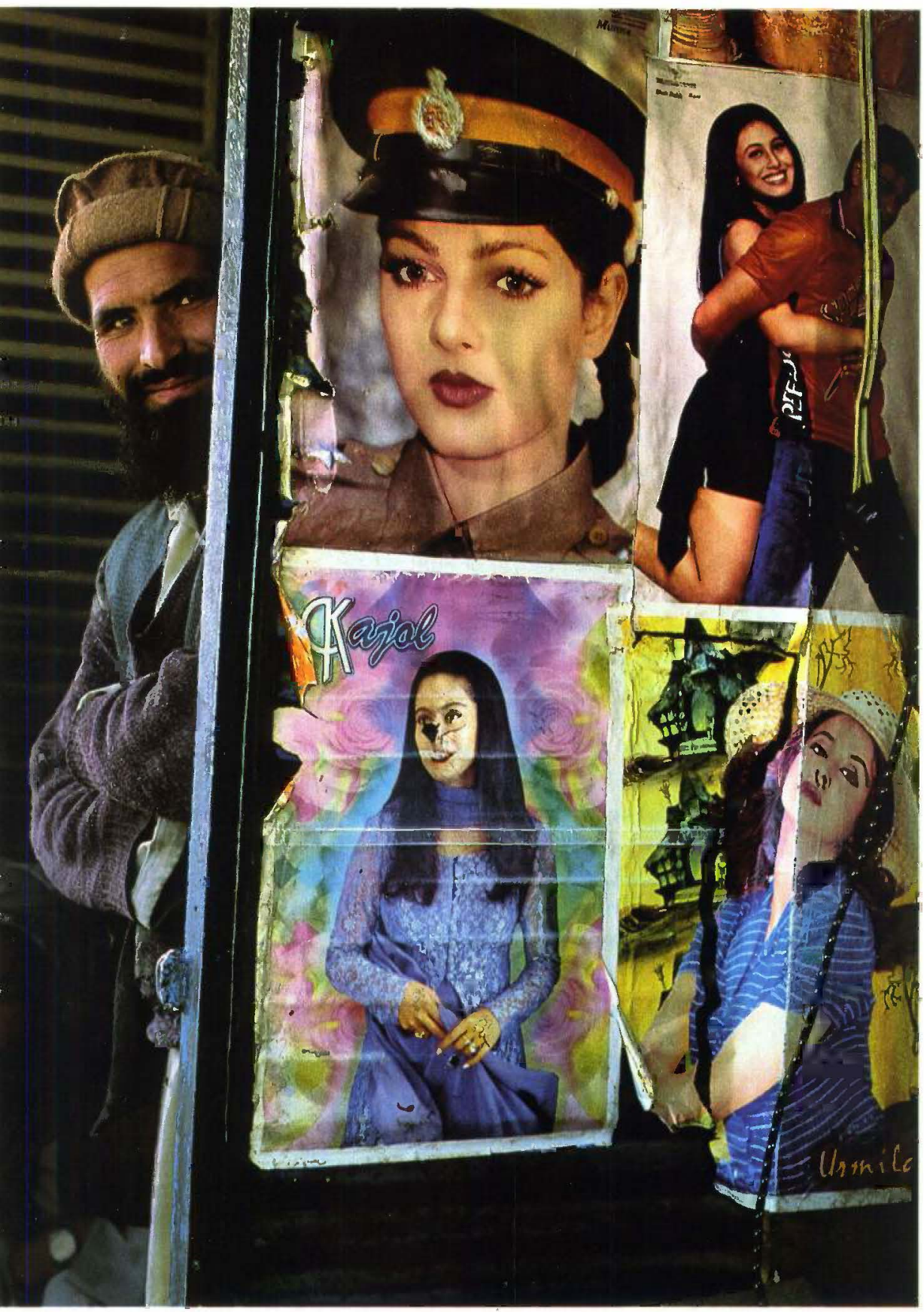

OUT OF HIDING Posters of popular Indian film stars and singers-once banned to "prevent idolatry"-reappeared almost overnight in Kabul after the Taliban fell from power. Now theoretically free to wear what they like, many Afghan women in this conservative country still don full-length veiled burkas, either from religious conviction or fear. "The mood is not right yet," says Shukriyah, a Kabul resident. "Many women are still nervous. The Taliban were not the only ones to cut back on our rights. Many of those now in power think the same way. It will take a long time to change that." 


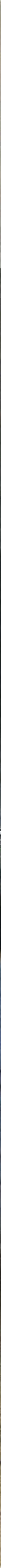




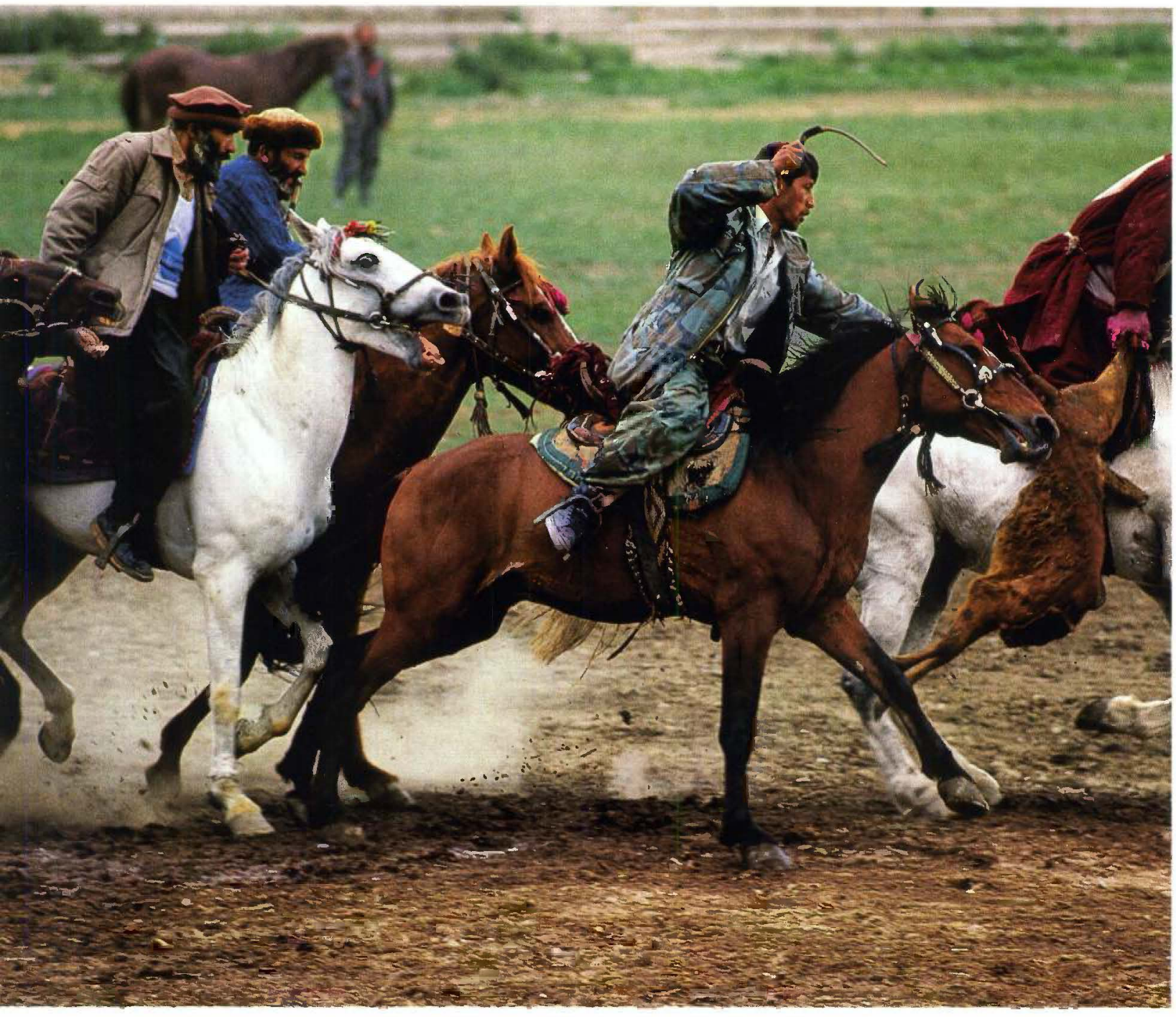

THE RACE IS ON Horsemen vie for a calf's headless carcass in this rough-and-tumble game of buzkashi, a traditional Afghan sport. This match, along with a parade of bodybuilders (top right) and other athletes, was part of a recent celebration marking the tenth anniversary of the end of communist rule. Discouraged or banned by the Taliban, sports are enjoying a comeback: Afghans aim to excel in wrestling during the 2004 Summer Olympics. Women who hope for greater independence are starting businesses such as beauty parlors (right), often with funds from international aid agencies. 

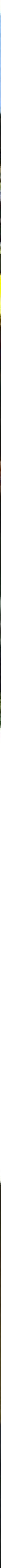

\section{Flush with freedom,}

Kabulis again display the pride and competitive spirit that has enlivened and sustained this ancient culture.

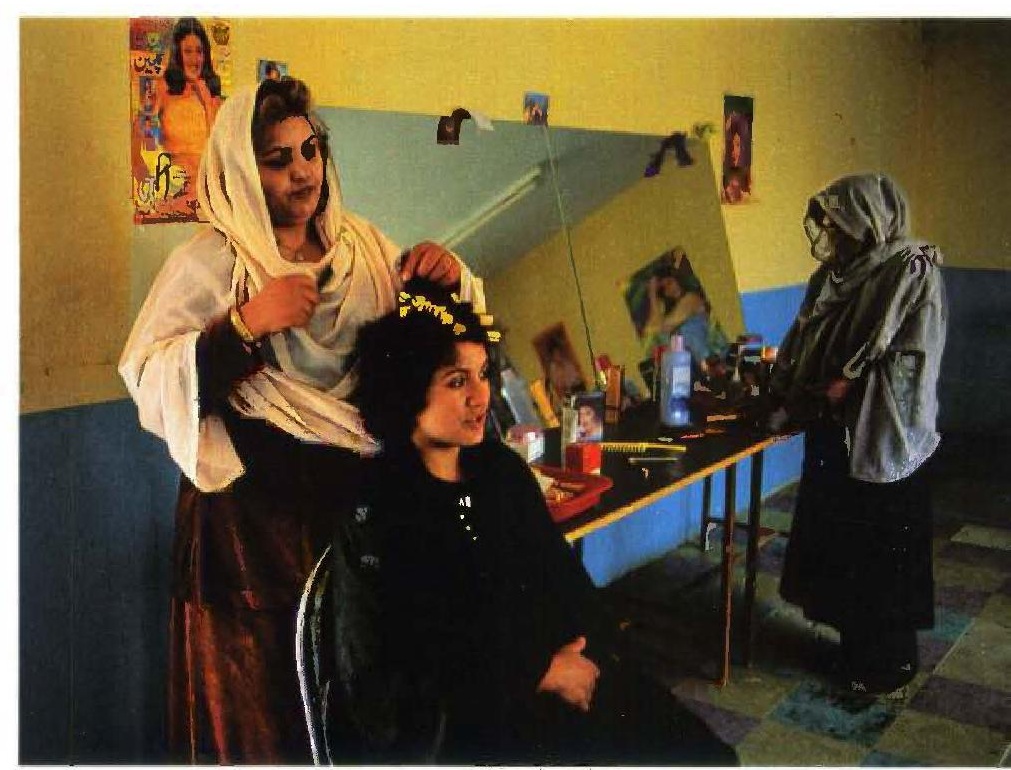




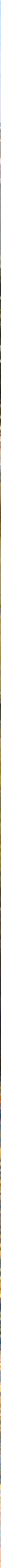


